\title{
O 'BOM PROFESSOR': UMA PERSPECTIVA DOS ESTUDANTES DE CURSOS SUPERIORES DE TECNOLOGIA EM GESTÃO
}

\section{The 'Good Teacher': A Perspective Of Superior Technology In Management Courses}

\author{
Carlos Roberto Miranda ${ }^{1}$ \\ Rafael Lima Medeiros Ferreira ${ }^{2}$ \\ Lúcia Villas Bôas ${ }^{3}$ \\ Rui Anderson Costa Monteiro ${ }^{4}$ \\ Roberto Gimenez ${ }^{5}$
}

\begin{abstract}
Resumo: O objetivo do presente artigo foi analisar a percepção de estudantes dos cursos de graduação tecnológica de gestão em relação ao desempenho docente. Tomaram parte deste estudo 120 (cento e vinte) discentes dos cursos de Graduação Tecnológica em Gestão de uma faculdade particular, situada na Zona Oeste da cidade de São Paulo/SP. Utilizou-se de abordagem quanti-qualitativa, com a aplicação de dois questionários aos discentes dos referidos cursos. Nas primeiras questões, utilizou-se a Técnica de Associação Livre de Palavras (TALP), por meio da qual os discentes apontaram uma qualidade pessoal e técnica dos docentes, nas duas últimas questões pontuaram tais qualidades utilizando-se dos critérios da Escala Likert. De modo geral, os resultados do presente estudo sugerem que, na ótica dos participantes da pesquisa, os atributos pessoais do professor seriam mais importantes do que os profissionais para o processo de aprendizagem.
\end{abstract}

Palavras-chave: Bom professor. Cursos de tecnologia. Tecnologia em gestão. Formação docente.

\footnotetext{
1 Graduado em Administração de Empresas pela Faculdade Flamingo e Mestre em Formação de Gestores Educacionais pela Universidade Cidade de São Paulo. Orcid: https://orcid.org/0000-0003-2151-7298. E-mail: crmiranda71@gmail.com.

2 Graduado em Biblioteconomia pela Universidade Federal do Amazonas e em Pedagogia pela Faculdade Intervale, Mestre em Políticas Públicas pela Universidade de Mogi das Cruzes e Doutorando em Educação pela Universidade Cidade de São Paulo, com bolsa da Coordenação de Aperfeiçoamento de Pessoal de Nível Superior. Servidor Público Federal, Bibliotecário-Documentalista da Universidade Federal do Amazonas. Orcid: https://orcid.org/0000-0002-6689-0689. E-mail: faelmedeiros.br@gmail.com.

${ }^{3}$ Graduada em História pela Universidade de São Paulo, Mestra e Doutora em Educação (Psicologia da Educação) pela Pontifícia Universidade Católica de São Paulo. Professora da Universidade Cidade de São Paulo. Orcid: https://orcid.org/0000-0001-5136-2392.E-mail: lucia.boas@unicid.edu.br.

${ }^{4}$ Graduado em Educação Física e em Pedagogia, ambos pela Universidade Nove de Julho, Mestre em Políticas Sociais pela Universidade Cruzeiro do Sul e Doutor em Educação pela Universidade Nove de Julho. Professor da Prefeitura Municipal de São Paulo e da Universidade Nove de Julho. Orcid: https://orcid.org/0000-0003-14106706. E-mail: profruianderson@gmail.com.

${ }^{5}$ Graduado em Educação Física pela Universidade de São Paulo e em Pedagogia pela Universidade Nove de Julho, Mestre e Doutor em Educação Física pela Universidade de São Paulo. Professor da Universidade Cidade de São Paulo. Orcid: https://orcid.org/0000-0002-4953-5941. E-mail: roberto.gimenez@unicid.edu.br.
} 
Abstract: The aim of this article was to analyze the perception of students in technological management undergraduate courses in relation to teaching performance. One hundred and twenty (120) students from the Technological Graduation courses in Management at a private college, located in the West Zone of the city of São Paulo/SP, took part in this study. A quantitative-qualitative approach was used, with the application of two questionnaires to the referred students . In the first questions, the Free Word Association Technique (TALP) was used, through which the students pointed out their personal and technical quality of the teachers, in the last two questions they scored such qualities using the criteria of the Likert Scale. In general, the results of the present study suggested that, from the perspective of the participants in the research, the personal attributes of the teacher would be more important than the professionals for the learning process.

Keywords: Good teacher. Technological courses. Management Technologies. Teacher preparation.

\section{Introdução}

Não é raro notarmos reclamações de estudantes com relação à dificuldade de alguns professores em mediar o conteúdo das disciplinas de forma clara, objetiva e direta, até mesmo os professores mais experientes, com excelente formação acadêmica, pedagógica, títulos, produção acadêmica, entre outras atribuições, também são alvos dessas queixas (BARBOSA, 2004).

A formação de profissionais qualificados para o mercado de trabalho tem relação direta com o planejamento de ensino focado no conteúdo das disciplinas e deve levar em consideração as possibilidades de transformação do estudante, além de atentar para a satisfação das necessidades da sociedade (BORDERNAVE; PEREIRA, 2002, ANASTASIOU; ALVES, 2005). Como contraponto, alega-se ser indispensável ao desenvolvimento do profissional uma formação mais generalista, humanista, crítica e reflexiva, independentemente da área e do nível de atuação. Neste processo de crescimento faz-se necessário compreender as percepções dos futuros profissionais acerca do desempenho dos professores em sala de aula.

Nas últimas décadas, de acordo com Penin (2001), presenciamos políticas educacionais em nível superior que transformaram a dinâmica das universidades, tanto públicas como privadas. Com o interesse do capital em torno da educação, a formação universitária se transformou em um grande mercado consumidor, afetando diretamente o 'ser docente'. Segundo Delors (2012), existe uma crise mundial que paira no ensino superior e que tem contribuído para a necessidade da reforma da educação. Trata-se de uma discussão antiga, envolvendo muitos atores do campo educacional, ansiosos por mudanças. Isso incita reflexões acerca do comportamento, da necessidade de constantes formações e do tempo de adaptação ao novo conceito em construção de educação superior.

Em face do avanço da globalização e do neoliberalismo presente de forma hegemônica em grande parte dos países, inclusive nas economias periféricas, esse modelo econômico atingiu praticamente todos os setores da sociedade, e com muito vigor, está influenciando a agenda das políticas educacionais, as quais acabam por impactar a carreira docente em todos os níveis (LOPES; CAPRIO, 2008).

Conforme destacam Sudbrack e Negro (2016), a década de 1990 foi marcada pelo crescimento da globalização, dando início ao processo de internacionalização da educação superior, e, consequentemente, a Organização Mundial do Comércio (OMC) passou a enxergar a educação como serviço, incentivando a expansão do mercado transnacional. 
Neste processo de internacionalização e transnacionalização, as instituições de ensino superior (IES) passaram a atuar de acordo com as práticas do mundo corporativo, reforçadas cada vez mais pelas diretrizes do Ministério da Educação (MEC). Como a demanda estava voltada a formar recursos humanos para o mundo do trabalho logo a estrutura de formação profissional passou a exigir, com maior veemência, um corpo docente com experiência profissional em um hibridismo entre a área acadêmica e o cenário corporativo, considerando titulação, pesquisas com resultados publicados em periódicos, docência e a experiência no mercado de trabalho (SUDBRACK; NEGRO, 2016).

As adaptações no ensino superior ainda estão em curso e para dar mais intensidade a este cenário, são identificadas as recentes mudanças promovidas pela reforma trabalhista e o crescimento desenfreado na modalidade de Ensino à Distância $(\mathrm{EaD})$, os quais comprometem cada vez mais o espaço de atuação dos professores em sala de aula, bem como a maneira de se enxergar os estudos e a carreira no magistério.

Considerando o contexto histórico e político contributivos para o atual cenário da educação superior brasileira, em especial os cursos superiores de tecnologia parecem sofrer impactos substanciais. Em parte, isto aconteceria em razão de sua orientação pragmática, voltada para atender às efetivas demandas do mercado. Um dos destes impactos refere-se ao considerável encurtamento destes cursos, tendo em vista o atendimento do imediatismo identificado no âmbito dos mais diferentes setores da economia. Na modalidade de formação profissional (graduação tecnológica), por exemplo, os cursos apresentam em sua maioria dois anos. Sem sombra de dúvida, outro impacto repousa na figura do professor, que necessita conhecer a realidade do mercado, ter relativa experiência em seu campo de atuação, bem como, na medida do possível, apresentar titulação e produção científica compatível com a área.

Estas constatações nos remetem a pensar no perfil docente. Tomando como base as possíveis influências dos professores nos processos de ensino e aprendizagem, cabe um questionamento acerca do perfil que melhor atenda às necessidades das IES e dos estudantes. Envolvido pelas tensões e conflitos, entende-se que a figura do professor assume papel importante: primeiro por estar em contato direto com os estudantes e, em segundo lugar, pelo fato de atuarem sobre ele inúmeras pressões que vão desde a exigência de resultados na aprendizagem, até a necessidade de contribuir efetivamente para a redução da evasão escolar por meio do bom relacionamento com as diferentes turmas em que ministra aula.

Diante do cenário, faz-se necessário refletir sobre a organização de referenciais para que gestores educacionais (coordenadores de curso) possam adotar critérios mais efetivos ao selecionar seu corpo docente e, consequentemente, estimular, capacitar e reter os talentos já existentes nas salas de aula. Assim, este estudo teve, por objetivo, conhecer as percepções dos estudantes de graduação tecnológica a respeito do professor no âmbito do processo de ensinoaprendizagem.

\section{Os cursos superiores de tecnologia no Brasil}

Os cursos de graduação tecnológica têm sua origem e composição na estrutura do ensino profissionalizante, da mesma forma que os antigos cursos técnicos em nível médio. Estes cursos são legalmente normatizados por Diretrizes Curriculares Nacionais estabelecidas pelo Conselho Nacional de Educação (CNE) e são direcionados para aplicação de conhecimentos científicos e tecnológicos nas mais variadas áreas do conhecimento, objetivando atender as demandas econômicas e necessidades do mundo corporativo no que se refere a recursos humanos. 
Assim, o ingresso nos cursos de graduação tecnológica enquadra-se no campo da educação profissional. Para Christophe (2010), a educação profissional consiste em uma variedade de processos educacionais, de formação e de treinamento institucionalizados e por meio das variadas modalidades de ensino, que olham com grande atenção e admiração a formação técnica dos alunos, tanto em nível médio quanto superior. Em geral, esses cursos são oferecidos por instituições formais de ensino (escolas e IES), por organizações patronais que compõem o sistema 'S' (por exemplo, Senai - Serviço Nacional de Aprendizagem Industrial e Senac - Serviço Nacional de Aprendizagem Comercial), organizações sindicais, comunitárias e as diversas organizações não governamentais. Sobre as modalidades de ensino, a que mais se destaca no fomento deste tipo de formação é a Educação à Distância (EaD).

Algumas discussões abordadas na educação superior no Brasil indicam que, durante muitos anos, as IES firmaram-se como instituições educacionais de excelência na formação de uma sociedade elitizada, bem como na produção do conhecimento científico e no desenvolvimento cultural em geral. Porém, de acordo com Kuenzer (1995) e Neves (2004), diante das exigências impostas ao mundo do trabalho para atender um mercado diversificado, a titulação em nível superior para o ingresso no mundo corporativo voltou suas atenções a um público cada vez mais diversificado, o que tem levado essas instituições a oferecerem cursos em novas áreas, com enfoque nas transformações tecnológicas.

O atual cenário econômico e produtivo mostra que a utilização de tecnologias complexas agregadas à produção, seja na indústria, no comércio ou fundamentalmente na área de serviços, caso comum nas economias periféricas da América Latina, exige sólida educação para formar os profissionais em meio às demandas impostas pelas grandes corporações internacionais e que se valem do exército de reserva para terem mão de obra barata e bem capacitada.

Diante deste contexto, a Lei de Diretrizes e Bases da Educação (LDB) 9.394, promulgada e publicada em 1996, representou o início dessa política educacional que buscou dar conta da realidade desencadeada pelo processo de reformulação profunda na educação superior. A LDB se colocou em uma posição de superar as perspectivas da educação reduzida à qualificação prática para desenvolver diversas competências ao trabalho dispondo, como diretriz básica, uma educação profissional integrada às diferentes formas de educação, ao mundo do trabalho, fundamentada na ciência e tecnologia e com vistas ao desenvolvimento constante do país (BRASIL, 1996).

O atual contexto econômico e social iniciado na década de 1990, somado às políticas educacionais e ao surto tecnológico após os anos 2000, gerou mudanças na história da educação profissional brasileira, sobretudo no que tange à proliferação da oferta dos cursos superiores de tecnologia no Brasil o que, consequentemente, nos faz pensar sobre o perfil dos professores e nas metodologias utilizadas uma vez que, em grande parte, o público atendido nesta formação é o estudante jovem, oriundo do ensino médio da rede pública e das classes socioeconômicas menos favorecidas.

\section{Concepções sobre a prática docente do ensino superior}

Estamos diante de um momento crucial da história do magistério superior e dos professores. Diante dos desafios atuais, torna-se mister repensar as nossas instituições e as práticas docentes. Se não o fizermos, estaremos a reforçar, mesmo que por inércia, tendências perigosas originadas na desregulação e na intensa privatização do setor que contribuem para a produção de pessoas com diploma, porém sem capacidade adequada de contextualização, 
reduzidos à reprodução mecânica em seus respectivos empregos e limitados, ou ausentes, na capacidade de transformação social.

A prática docente precisa, na medida do possível, proporcionar aos discentes momentos únicos de prazer em aprender, buscando refletir mais sobre o tema abordado em sala de aula. É ainda recurso importante ao professor de ponderação do conteúdo da disciplina e avaliação sobre os métodos utilizados, portanto, é preciso o desenvolvimento de certas habilidades e competências docentes.

Concordamos com Imbernón (2006) quando este afirma ser necessário aos professores romperem com a imagem de um profissional demasiadamente técnico, que segue modelos prescritos, buscando a construção de um profissional que inova a partir de uma atuação mais dinâmica, reflexiva, ética e crítica no contexto educativo trazendo a possibilidade de transformar a si próprio, a profissão docente e os contextos educativos.

Reconhecidamente, as universidades brasileiras, nas últimas décadas, têm buscado melhorar o nível de qualificação acadêmica de seus professores, iniciando com o aumento do quadro a partir da titulação, priorizando os mestres e doutores, segundo o preconizado na LDB 9.394/96. Porém, embora possuam esses títulos acadêmicos, os professores não têm dado a devida importância à sua formação direcionada ao magistério, ou seja, ao preparo para exercer a função do ensinar, o que alguns autores alertam sobre as lacunas existentes na formação dos docentes ao ensino superior (BORDENAVE; PEREIRA, 1977; ABREU et al., 1997, GIL, 2008).

De acordo com Penin (2001), constata-se, atualmente, a contratação de docentes especializados no seu campo de conhecimento, até porque costuma ser exigência para que seja selecionado e admitido, mas este professor não apresenta apropriação de competências pedagógicas, pressupondo-se que ter um bom domínio sobre o assunto é o suficiente para ser um(a) 'bom(a) professor(a)', exaltando o conhecimento teórico e experiência prática na área de formação/atuação em detrimento de suas competências didático-metodológicas.

Em tese, o que norteia essa ausência de preocupação com seus recursos didáticos é o fato dos estudantes universitários serem adultos, estarem motivados pela profissionalização, entendendo que estes já teriam maior facilidade de compreender o conteúdo ensinado. Reconhecidamente, esta visão merece ser analisada criticamente, com vistas a um melhor alcance das expectativas que se tem para o ensino superior. As várias iniciativas de avaliação institucional indicam com relativa frequência, que os discentes, ao falarem sobre seus professores, evidenciam as competências técnicas da profissão e apontam a falta de didática com o uso quase exclusivo da aula expositiva e com pouca participação dos estudantes (BORDENAVE; PEREIRA, 1997).

Em outras palavras, o que se observa na prática é a existência de lacunas no desempenho desses docentes. É fundamental que as instituições de ensino superior busquem professores com vocação para ensinar e promovam formação constante ao seu corpo docente, munindo-os de apoio e incentivos para trabalharem de forma mais eficiente possível obtendo, assim, resultados mais efetivos por meio do respeito ao processo de aprendizagem, facilitando-o e incrementando-o (SANTOS, 2001).

Em particular, esse aspecto carece de uma discussão mais aprofundada junto aos cursos tecnológicos, identificados por demandas marcadamente associadas aos contextos do mercado de trabalho. Mais especificamente no Brasil, estes cursos apresentam grande número de estudantes e compõem o maior percentual de discentes das instituições privadas, sobretudo pelos valores acessíveis e tempo encurtado de formação. 
Em contrapartida, esses estudantes conseguem chegar ao ensino superior, mediante muito sacrifício individual e familiar e não são raras as ocasiões em que se deparam com dificuldades no percurso da graduação, seja de ordem financeira ou pedagógica. É possível pressupor que estas dificuldades possam receber influências dos processos pedagógicos, o que justifica a necessidade de se analisar as concepções dos estudantes sobre seus professores.

Diante destas constatações, o presente artigo tem por objetivo analisar a percepção dos estudantes dos cursos de graduação tecnológica de gestão em relação ao desempenho do docente do ensino superior no âmbito do processo ensino-aprendizagem.

\section{Procedimentos metodológicos}

Esta investigação teve como objeto de estudo os cursos tecnológicos, esta escolha se deu pelo crescimento acentuado que esta modalidade de cursos teve nos últimos 10 (dez) anos. Os cursos de graduação tecnológica apresentaram o maior índice de crescimento em termos percentuais, registrando aumento de $119,4 \%$, ao mesmo tempo em que os cursos de Licenciatura registraram alta de 8,9\% no mesmo período (INEP, 2018).

Os procedimentos metodológicos foram desenvolvidos a partir da seguinte questão norteadora: 'Quais as percepções dos estudantes dos cursos tecnológicos na área de gestão sobre o desempenho do(a) bom(a) professor(a) em sala de aula?'

O instrumento de coleta de dados foi submetido ao Comitê de Ética em Pesquisa da Universidade Cidade de São Paulo e encontra-se protocolado sob o número 1.510.638. Após aprovação e autorização do Comitê, o instrumento foi enviado virtualmente para 160 (cento e sessenta) estudantes por meio da ferramenta Google Forms, estando disponível para ser respondido durante todo o segundo semestre letivo de 2019.

Dos 160, tivemos a participação de 120 (cento e vinte) discentes entre homens e mulheres, na faixa etária entre 18 (dezoito) e 30 (trinta) anos, dos cursos de graduação em gestão tecnológica de uma IES localizada na Zona Oeste da cidade de São Paulo/SP.

Foram utilizados como instrumento de coleta de dados, 02 (dois) formulários contendo duas questões abertas em cada um deles. O primeiro visou identificar as qualidades pessoais e, o segundo, as qualidades técnicas dos(as) professores(as) dos cursos de gestão tecnológica. $\mathrm{Na}$ primeira questão, utilizou-se a Técnica de Associação Livre de Palavras (TALP), a qual faz parte da chamada técnica projetiva e orientada pela hipótese de que a estrutura psicológica do aluno se torna consciente por meio de manifestações de condutas (COUTINHO; BÚ, 2017). Na segunda questão foi utilizada a Escala Likert para avaliar as qualidades do(a) professor(a). Tais qualidades foram adaptadas do Questionário de Avaliação de Ensino e Metodologia de Avaliação de Professores Universitários (GARGALLO et al., 2009).

Todos os participantes foram devidamente instruídos a responderem a primeira questão de cada questionário, e somente depois de respondida, passaram a ter acesso à segunda questão, a fim de evitar qualquer tipo de influência das qualidades listadas no segundo instrumento. Por fim, destacamos que os participantes assinaram o Termo de Consentimento Livre e Esclarecido com todas as informações necessárias da pesquisa. 


\section{Resultados e discussão da pesquisa}

\subsection{Instrumento relativo às 'qualidades pessoais' do(a) 'bom(a) professor(a)'}

A partir do uso da Técnica de Associação Livre de Palavras (TALP), foram selecionadas apenas os vocábulos que se repetiram duas ou mais vezes. Entendeu-se que essa frequência indicaria as qualidades de maior expressividade na percepção dos participantes. A primeira questão foi: Cite uma única palavra referente à qualidade pessoal de um(a) 'bom(a) professor(a)':

Figura 1 - Qualidades pessoais do(a) 'bom(a) professor(a)'

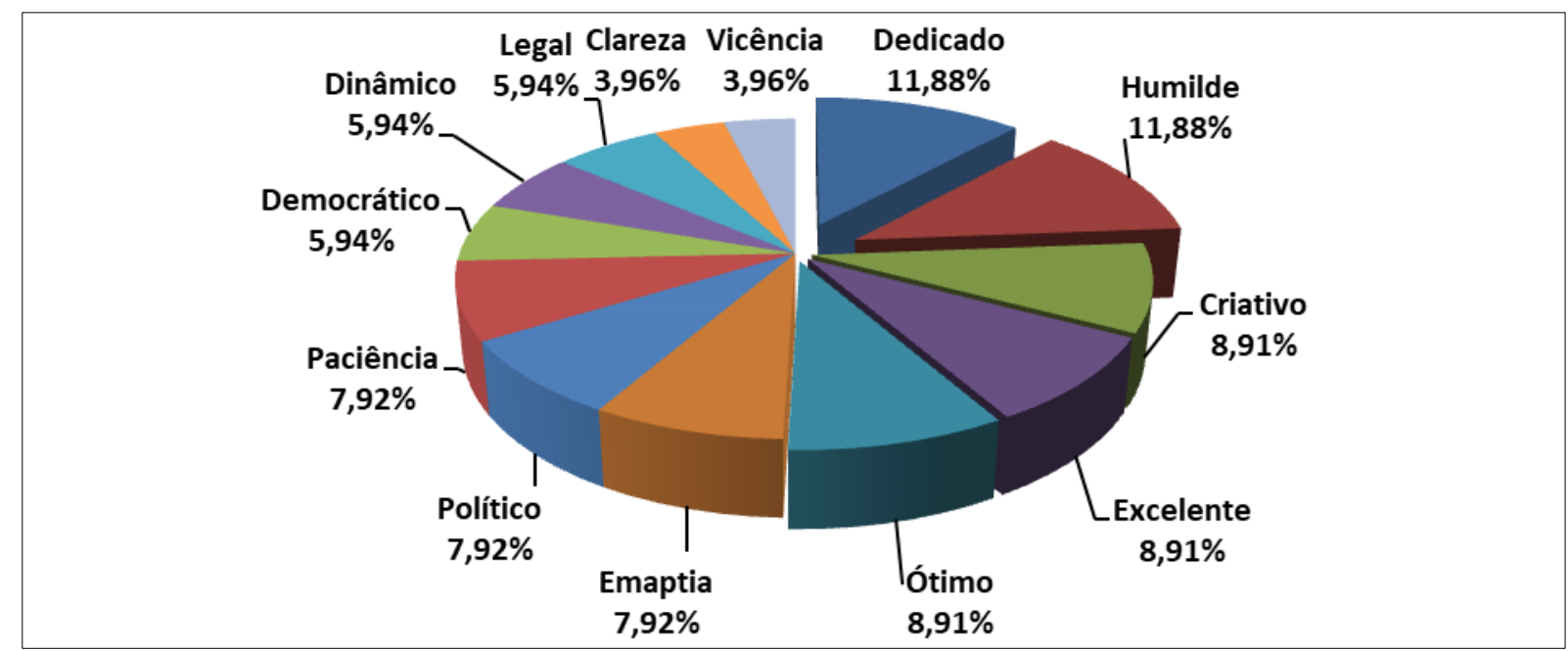

Fonte: autoria própria (2021)

Diante do resultado, cabe destacar as características - 'humilde' e 'dedicado' - com $11,88 \%$ cada, apontadas pelos respondentes como sendo as qualidades pessoais mais citadas. Acreditamos que este total de $23,76 \%$ (somando as duas) denota ao professor a necessidade de estar comprometido com a profissão e com os seus alunos, mas sem perder a capacidade de relacionamento e proximidade. Isso pode ser compreendido nas palavras de Schwartz e Bittencourt:

As qualidades esperadas de um 'bom professor' variam de acordo com o contexto histórico, cultural e social. Quando pensamos em uma instituição nos moldes tradicionais, estas características poderiam estar relacionadas à importância do saber dos mestres, ou ainda à autoridade destes em sala de aula. No entanto, nas instituições que se dizem próximas às vertentes mais contemporâneas em educação, talvez estes atributos circulem mais na direção da centralidade do aluno nos processos de ensino e de aprendizagem, o que exige uma relação mais próxima e dialógica entre professores e alunos, entre ensino e aprendizagem (2012, p. 09).

'Criativo', 'excelente' e 'ótimo' - surgem em segundo lugar como qualidades pessoais escolhidas pelos estudantes. Em geral, é bastante complexo interpretar a percepção dos respondentes sobre esses adjetivos, mas acreditamos que 'ser excelente' e 'ser ótimo' podem denotar maneiras semelhantes de dizer que o (a) professor (a) não deve medir esforços para atender as expectativas dos alunos integrando domínio de conteúdo e capacidade de integração. 
Consideradas importantes para 17,82\% dos participantes temos 'ser criativo' e 'ser excelente', que se tratam de qualidades pessoais a ser desenvolvidas pelos (as) professores (as), contribuindo assim, para que o papel do(a) docente em sala de aula atenda às necessidades e expectativas quanto a uma aula dinâmica e afastada dos modelos tradicionais em que o professor explana e o aluno apenas ouve. A falta dessas qualidades talvez crie dificuldades no processo de ensino aprendizagem, as quais podem ser reforçadas nas palavras de Anastasiou (2010, p. 78): "quando o professor é desafiado a atuar numa visão diferente em relação aos processos de ensino e aprendizagem, poderá encontrar dificuldades, até mesmo pessoais, de se colocar numa diferenciada ação docente". Concomitante a isso, a falta de interesse por parte dos (as) professores (as) em se atualizar e em ensinar, colabora na influência negativa da aprendizagem dos alunos (LAZZARIN; NAKAMA; JÚNIOR, 2007).

'Ter empatia', 'ser político' e 'ser paciente' aparecem como qualidades pessoais apresentadas pelos estudantes em um terceiro estágio, mas não menos importante, se levarmos em consideração o fato de serem qualidades pessoais daqueles(as) que sabem se colocar no lugar do próximo.

É fato que no decorrer da graduação, estudantes e professores formam uma relação de convívio diário, seja por meio das aulas teóricas ou pelas práticas, e isso acontece mesmo antes do início das atividades. Neste contexto, ambos tendem a enxergar um ao outro de maneira superficial e pré-concebida, comprometendo as relações, por isso, quanto maior for o contato, melhor será a resposta no processo de ensino-aprendizagem: "Tanto professores quanto os discentes criam uma imagem idealizada daquilo que esperam que seja um educador e, do outro lado, um aluno perfeito. Apesar de idealizadas, essas imagens cultivadas são veementemente relevantes para o campo educacional" (LOPES, 2012, p. 5).

A autora ainda esclarece que o aspecto humano das relações deve ser o principal fator para possibilitar a relação mais próxima entre professores e alunos, sendo que a aproximação afetiva entre estes não tem, necessariamente, como resultado, a inversão da hierarquia em sala de aula.

No quarto nível surgem qualidades pessoais como - 'democrático', 'dinâmico' e 'legal' - e na sequência, finalizando as qualidades apontadas pelos alunos - 'ser claro' e 'ter vivência'.

As qualidades pessoais 'ótimo', 'empatia', 'paciência' e 'legal' podem estar relacionadas às questões de afetividade, assunto recorrente no meio acadêmico, pois a afetividade é o recurso de mediação e conexão realizada no processo de ensino-aprendizagem, sendo única, entre o professor e aluno (OLIVEIRA, 1992, BOCK; FURTADO; TEIXEIRA, 2011). Vale destacar que os estudantes do ensino superior, principalmente das instituições privadas, são jovens oriundos das escolas públicas, não tendo muitas vezes noção da rotina universitária, ainda que bastante sensíveis para a construção de novas relações interpessoais e facilmente alinhados à dinâmica da universidade.

Aschidamini, Cristiano e Perondi (2014), consideram importante que durante o ensino superior os alunos não sejam apenas instruídos de forma teórica conceitual, mas também recebam formação adequada a fim de se prepararem para as necessidades exigidas pelo mercado de trabalho. É necessário buscar reduzir a distância existente entre alunos que ingressam no ensino superior e as respectivas instituições que os acolhem, isto é possível por meio da alteração nas características da formação universitária, procurando atender às mudanças constantes na sociedade globalizada no caminho da formação de sujeitos adaptáveis a contextos intensamente voláteis. 
Vejamos a seguir o resultado da pesquisa sobre as qualidades pessoais apresentadas pelos respondentes utilizando-se da Escala Likert. Os participantes responderam ao seguinte enunciado: Classifique de acordo com a escala abaixo quais as qualidades pessoais que você enxerga para ser um(a) 'bom(a) professor(a)':

Tabela 1 - Resultado do instrumento relativo às qualidades pessoais do(a) 'bom(a) professor(a)'

\begin{tabular}{lccccc}
\hline $\begin{array}{l}\text { Qualidades } \\
\text { pessoais }\end{array}$ & $\begin{array}{c}\text { Nem um pouco } \\
\text { importante }\end{array}$ & $\begin{array}{c}\text { Um pouco } \\
\text { importante }\end{array}$ & Importante & $\begin{array}{c}\text { Muito } \\
\text { importante }\end{array}$ & $\begin{array}{c}\text { Extremamente } \\
\text { importante }\end{array}$ \\
\hline Simpatia & 0 & 0 & 12 & 42 & 66 \\
Bom humor & 0 & 0 & 18 & 54 & 66 \\
Compreensão & 0 & 6 & 24 & 24 & 72 \\
Coerência & 0 & 0 & 0 & 48 & 78 \\
Humildade & 0 & 0 & 6 & 36 & 72 \\
\hline Empatia & 0 & 0 & 12 & 36 & 36 \\
\hline Curiosidade & 0 & 0 & 6 & 78 & 54 \\
\hline Flexibilidade & 0 & 0 & 12 & 54 & 78 \\
\hline
\end{tabular}

Fonte: autoria própria (2021)

É possível identificar na Tabela 1 as qualidades pessoais 'humildade', 'empatia', 'coerência' e 'compreensão' em destaque. Nas palavras de Schwartz e Bittencourt (2012), reforça-se a qualidade pessoal ideal de um(a) professor(a) - 'ser coerente' - como sendo uma característica pessoal indispensável na visão dos estudantes.

Percebemos aqui o que foi encontrado quando da aplicação da Técnica de Associação Livre de Palavras (TALP), em que os respondentes apontam - 'ser humilde' e 'ser empático' como uma das principais qualidades pessoais do(a) bom(a) professor(a) em sala de aula. Em outras palavras, os dois recursos (instrumentos) utilizados registraram resultados semelhantes. Dentre os participantes, 78 (setenta e oito) respondentes apontaram - 'ser humilde', e 72 (setenta) indicaram - 'ter empatia' - como qualidades pessoais relevantes aos(às) professores(as) atuantes nos cursos de gestão tecnológica.

'Ser compreensivo' é característica importante aos docentes segundo 66 (sessenta e seis) respondentes e isso aparece logo após a qualidade 'ter empatia'. Isso pode ser compreendido, nas palavras de Covey (2014), que a dificuldade em ter empatia se deve ao julgamento préconcebido das pessoas com base na nossa própria história de vida, ou seja, não percebemos que cada pessoa é única dotada de histórias e experiências próprias. Conforme o autor, para sermos empáticos, precisamos aprender primeiro compreender para depois sermos compreendidos, escutando ativamente com o coração aberto. Ele ainda afirma que grande parte das pessoas ouve com a intenção de responder, já se preparando para falar, filtrando tudo através dos seus próprios paradigmas.

Fukuda e Pasquali (2002) reforçam esse pensamento quando referenciam alguns aspectos requeridos ao 'bom (a) professor (a)', entre eles - 'empatia' - que agrupa a necessidade 
de entender as necessidades pessoais, psicológicas e escolares; ter consciência do contexto social e psicológico; e lidar com as necessidades psicológicas dos alunos.

Para ter boa relação empática, a iniciativa deve partir da pessoa com mais conhecimento, neste caso, o professor, portanto é coerente ter certa força de vontade, um desejo de contribuição, humildade e interesse em estabelecer boas comunicações. Christi (2015) coloca a empatia como um medidor eficaz da maturidade humana:

\begin{abstract}
Quando eu falo em atenção empática, estou me referindo à atenção com a finalidade de compreender. Ou seja, procuro primeiro compreender, realmente compreender. Trata-se de um paradigma completamente diferente. A atenção empática entra dentro do quadro de referências da outra pessoa. Se você olhar para dentro dele, vê o mundo como ela o vê compreende seu paradigma, compreende o que ela sente. (COVEY, 2014, p. 158).
\end{abstract}

Novamente as discussões acima evidenciam o papel das qualidades relacionadas à afetividade entre professores e estudantes e sua influência na formação discente. Para Silva e Zucolotto (2019), tais discussões sobre afetividade ganham volume e espaço com este enfoque, pois existem inúmeras discussões sobre aspectos de interferência nos processos de ensino e aprendizagem. Dentre eles, destacamos o ganho de confiança, fundamental para a crescente autonomia desejada junto aos alunos.

Para Wallon (1968, p. 128), afetividade é algo próprio ao ser humano, "encontrando-se ligada às suas necessidades e automatismos elementares, imediatamente consecutivos ao nascimento". Vygotsky (1998), aponta que o comportamento do indivíduo é constituído em parte pelas suas origens biológicas e também por sua origem sociocultural, sendo que uma é dependente da outra. Portanto, é necessário que se compreenda que a afetividade apenas será internalizada graças à interação dos estudantes com seus professores (ISAIA, 2006).

\title{
5.2 Instrumento relativo às qualidades técnicas do (a) 'bom (a) professor (a)'
}

Apresentamos os resultados da pesquisa com os alunos, a partir da Técnica de Associação Livre de Palavras (TALP), em que se adotou o mesmo critério do primeiro questionário, ou seja, foram selecionadas apenas as palavras que se repetiram mais de duas vezes na coleta dos dados. Os sujeitos desta pesquisa responderam à seguinte questão: Cite uma única palavra referente à qualidade técnica de um (a) 'bom (a) professor (a)': 
Figura 2 - Qualidades técnicas do (a) 'bom (a) professor (a)'

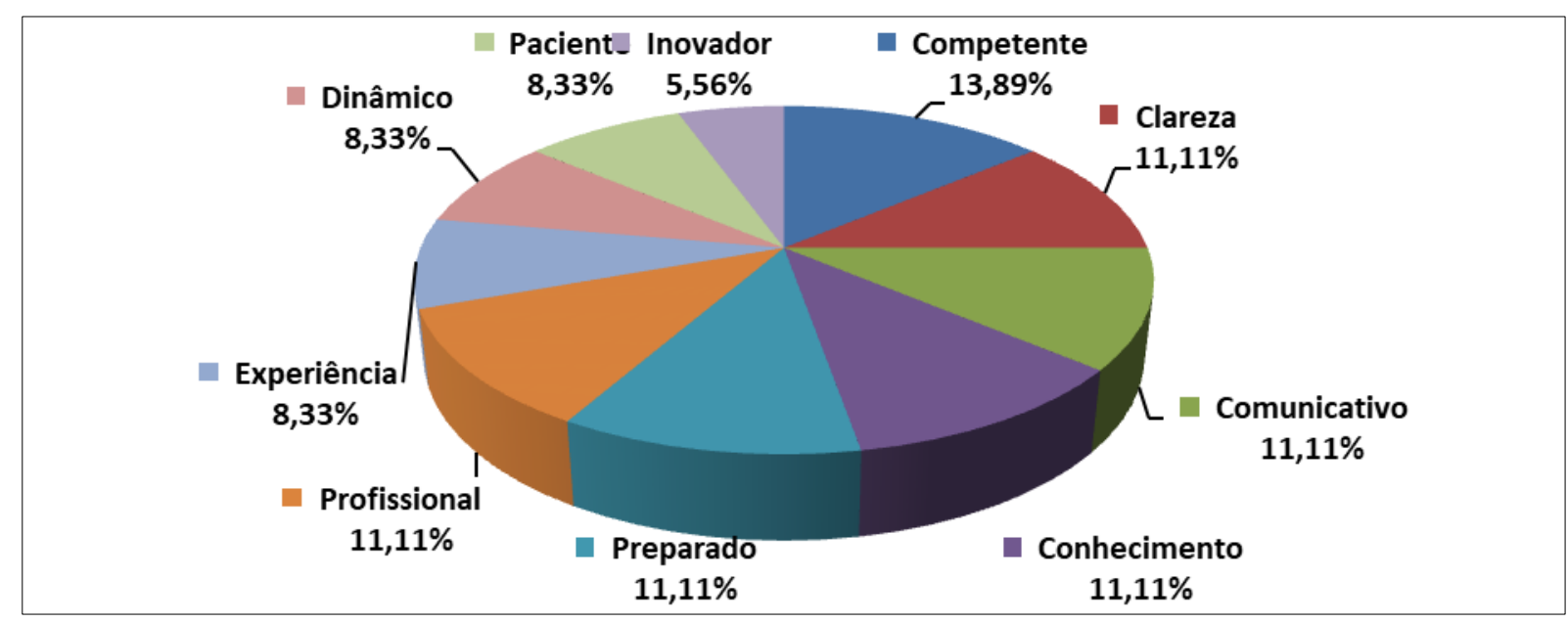

Fonte: autoria própria (2021)

Dentre os participantes, 15 (quinze) participantes elegeram - 'competência' - como sendo uma das principais qualidades técnicas do (a) 'bom (a) professor (a)'; 12 (doze) escolheram -'clareza', 'comunicativo', 'conhecimento', 'preparado' e 'profissional'; 09 (nove) apontaram - 'experiência', 'dinâmico' e 'paciente' e; 06 (seis) indicaram - 'inovador'.

Observamos que em relação às qualidades técnicas do (a) 'bom (a) professor (a)', os estudantes priorizam aspectos arraigados a um ensino mais técnico, tais como, 'competência', 'conhecimento' e 'clareza' sobre sua disciplina. Tais aspectos vão de encontro das palavras de Schwartz; Bittencourt (2012), que relacionam ao ensino tecnicista a necessidade de possuir competência, responsabilidade e comprometimento sobre a disciplina. Afirmam ainda que tais qualidades são próximas à ideia de habilidades e competências serem indispensáveis ao professor gestor de sua própria carreira.

Segundo Lazzarin, Nakama e Júnior (2007), o docente tem papel fundamental no processo de ensino-aprendizagem, é considerado responsável pela transmissão de conhecimentos e das trocas de experiências. Isso nos leva a compreensão sobre o seu papel fundamentado na expertise do mundo do trabalho, bastante valorizado pelos estudantes que almejam a formação em nível superior nas áreas de gestão.

As qualidades técnicas apontadas pelos discentes de graduação tecnológica em gestão, tais como 'clareza', 'comunicativo', 'conhecimento', 'preparado' e 'profissional', nos remetem às palavras de Fukuda e Pasquali (2002), que apresentam uma revisão da literatura inerente às características do professor, referenciando aspectos requeridos ao docente eficaz, em torno da organização de algumas competências, tais como, conhecimento: que inclui ter conhecimento das áreas do conteúdo a serem ensinadas e de didática: subentende criar métodos de ensino efetivos para facilitar a aprendizagem, instruir, lidar com o processo de aprendizagem e usar técnicas de ensino que otimizem a aprendizagem dos alunos.

Martins (2004), respondendo à questão - "que características definem um bom professor?" - indica alguns aspectos: domínio de conteúdo: o professor deverá dominar os conteúdos da matéria ou disciplina que leciona, demonstrando conhecimentos profundos sobre o tema, e comunicação: o professor deverá expor com clareza e didática. Um bom professor será tão mais competente quanto melhor souber se comunicar, falando e escrevendo. 
Em suma, as habilidades de comunicação verbal e escrita são requisitos para o êxito de, praticamente, todas as profissões. Para o professor, tratam-se de habilidades essenciais e indispensáveis para o ensino e ao exercício profissional. Tecnicamente, falar e escrever bem deveriam ser qualidades básicas de qualquer cidadão oriundo de sistemas de ensino de educação básica de qualidade.

A seguir, apresentam-se os resultados da pesquisa sobre as qualidades técnicas apontadas pelos alunos, utilizando-se da Escala Likert. Os participantes responderam ao seguinte enunciado: Classifique de acordo com a escala abaixo quais as qualidades profissionais que você enxerga para ser um (a) 'bom (a) professor (a)':

Tabela 2 - Resultado do instrumento relativo às qualidades técnicas do (a) 'bom (a) professor (a)':

\begin{tabular}{|c|c|c|c|c|c|}
\hline $\begin{array}{l}\text { Qualidades } \\
\text { Profissionais }\end{array}$ & $\begin{array}{l}\text { Nem um pouco } \\
\text { importante }\end{array}$ & $\begin{array}{l}\text { Um pouco } \\
\text { importante }\end{array}$ & Importante & $\begin{array}{c}\text { Muito } \\
\text { importante }\end{array}$ & $\begin{array}{l}\text { Extremamente } \\
\text { importante }\end{array}$ \\
\hline $\begin{array}{l}\text { Experiência } \\
\text { profissional }\end{array}$ & 0 & 0 & 0 & 30 & 90 \\
\hline $\begin{array}{l}\text { Reconhecimento no } \\
\text { mercado }\end{array}$ & 0 & 0 & 12 & 78 & 30 \\
\hline Produção científica & 0 & 6 & 6 & 78 & 30 \\
\hline $\begin{array}{l}\text { Capacidade de se } \\
\text { comunicar }\end{array}$ & 0 & 0 & 0 & 18 & 102 \\
\hline $\begin{array}{l}\text { Capacidade de liderar } \\
\text { pessoas e grupos }\end{array}$ & 0 & 0 & 0 & 30 & 90 \\
\hline $\begin{array}{l}\text { Competências no uso } \\
\text { de tecnologias }\end{array}$ & 0 & 0 & 12 & 66 & 42 \\
\hline
\end{tabular}

Fonte: elaborado pelos autores, 2021

Neste quadro, assim como na primeira questão, são identificados novamente aspectos ligados ao método tecnicista, isso porque percebemos se tratar de qualidades técnicas importantes apontadas por 102 (cento e dois) respondentes - 'experiência profissional' - porém, podemos entender de nada adiantar essa abordagem técnica, se acaso o professor não for dotado de - 'capacidade de se comunicar' - eleita por 102 (cento e dois) participantes e - 'capacidade de liderar pessoas e grupos' - apontada por 90 (noventa) estudantes.

De acordo com Martins (2004), além das características que definem um bom professor, tais como, domínio do conteúdo e comunicação, o professor também deverá ter um bom relacionamento com seus alunos, sendo justo, responsável, respeitador e saber ouvi-los. Aqui entra uma qualidade pessoal, já discutida anteriormente - 'empatia' - indispensável à inteligência emocional, que pode ser resumida com a habilidade no relacionamento com pessoas.

A qualidade técnica - 'capacidade de liderar pessoas e grupos' - também é reforçada por Fukuda e Pasquali (2002) quando estes se referem à administração da sala de aula. Para esses autores, todo professor deve ser capaz de usar aconselhamento e técnicas de avaliação para lidar com os problemas de disciplinas e comportamentos inapropriados dos alunos, monitorar e supervisionar sua postura, mantendo a ordem e a disciplina. 


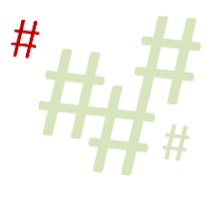

No caso da 'experiência profissional' -'capacidade de se comunicar' e da 'capacidade de liderar pessoas e grupos' - encontramos fundamentação teórica em Maicas (1996), em que o autor descreve o papel do professor agrupado em sete funções principais:
a) O professor como experiente em instrução;
b) O professor como motivador;
c) O professor como organizador;
d) O professor como líder;
e) O professor como orientador;
f) O professor como experiente ambiental;
g) O professor como modelo.

Dentre as qualidades técnicas classificadas pelos estudantes como sendo muito importantes, destacam-se o 'reconhecimento no mercado' e as 'produções científicas'. Conforme Assis e Bonifácio (2008), quando não há desenvolvimento da produção científica, o conhecimento proporcionado pelas IES limita-se apenas ao ensino em sala de aula. Essa situação nos conduz à compreensão do risco iminente em sala de aula da retroalimentação da cultura do ambiente profissional sem reflexão, já que o distanciamento da pesquisa pode conduzir o docente a certo grau de limitação pelo fato de se fundamentar em sua empiria sem considerar os aspectos do conhecimento científico na formação e no exercício profissional, ou mesmo pelo fato deste se respaldar em informações ultrapassadas.

Fávero (1994) afirma que a produção científica nem sempre é parte integrante nos cursos de graduação. Logo, quando a pesquisa deixa de ser usada como estratégia pedagógica durante a graduação, essa situação estará em contraposição à finalidade primordial da universidade: a produção e socialização do conhecimento por intermédio do ensino, da pesquisa e da extensão. Segundo Bridi (2004, p. 74), "para alguns professores, a introdução à pesquisa começa na graduação, na sala de aula, quando o professor desperta o interesse do aluno em aprofundar seus estudos na área de sua disciplina”.

De acordo com Assis e Bonifácio (2008), é necessário que os alunos tenham a possibilidade de desenvolver atividades de pesquisa na própria sala de aula, nas disciplinas oferecidas pelo curso de graduação, principalmente naquelas disciplinas específicas que trabalham metodologia científica. Neste sentido, Demo (2005), postula que a pesquisa científica é entendida como princípio científico e educativo, é a maneira do aluno saber fazer, como também de refazer seu conhecimento, e assim, educar.

A pesquisa acadêmica pode ser considerada como uma atividade pedagógica que tem o intuito de despertar o espírito de busca intelectual de forma autônoma. É necessário aprender as formas de problematizar, solucionar esses problemas, indicar respostas adequadas, entre outras demandas. Portanto, a pesquisa acadêmica é, antes de tudo, exercício, preparação (SANTOS, 2004).

Em suma, muitas das qualidades pessoais, como as técnicas, parecem convergir entre si na opinião da maioria dos estudantes do curso de graduação tecnológica. Tais características são importantes no exercício do magistério superior, desde a preparação das aulas, passando pela construção das relações interpessoais e desenvolvidas nas práticas docentes. 


\section{Considerações finais}

Diante de um mercado cada vez mais competitivo e, principalmente, com os entraves na nossa economia, é provável que as IES tenham que repensar seus currículos para uma formação de profissionais que atendam às demandas socioeconômicas do país e caminhem para a otimização dos índices de empregabilidade e perspectiva de crescimento profissional.

Para isso, acredita-se que a construção do projeto pedagógico dos cursos de gestão tecnológica deva observar o cenário composto das interações entre as IES, as normativas governamentais e o interesse social, este por sua vez, manifestado pela demanda de mercado e aspirações dos futuros profissionais. Para tanto, é provável ser necessário estabelecer novas relações professor-aluno, na qual o docente seja capaz de refletir sobre sua importância no processo ensino-aprendizagem, procurando caminhos alternativos para se tornar protagonista na formação e, onde o (a) professor (a) se torne facilitador (a) e mediador (a). Estas condições impõem outras demandas ou peculiaridades à atuação dos docentes, as quais perpassam por sua história profissional e perfil pessoal.

Cabe aos docentes estimularem a capacidade do discente no sentido dos quatro pilares da educação (DELORS, 2012), mas com destaque a esses dois - "aprender a conhecer e aprender a fazer", tornando-o capaz de buscar conhecimentos necessários à sua atualização a fim de se afastarem da informação superficial e colocá-los em prática, mostrando a responsabilidade pela educação permanente e o espírito crítico. Em meio a este processo, um fator que parece ser facilitador, diz respeito às características pessoais dos docentes.

No presente estudo, estudantes em geral destacaram as características pessoais dos professores como cruciais para o seu processo de formação. É possível que nos cursos avaliados e diante do perfil discente, identificado por dificuldades financeiras e de formação na Educação Básica, estas características prevaleçam em relação ao domínio técnico de assuntos específicos da profissão.

Entende-se que as IES precisam estar cientes da importância do papel do docente no processo ensino-aprendizagem em sala de aula, propiciando-lhes condições favoráveis de trabalho, remuneração mais justa e atrativa, subsídios para cursos de capacitação didáticopedagógicos, a fim de formar profissionais que questionem a realidade, busquem soluções mais criativas e contribuam para o desenvolvimento do país.

Gestores da área da educação superior precisam direcionar constantemente seus esforços na captação, seleção e retenção de novos talentos para formar um corpo docente mais comprometido com os processos de ensino-aprendizagem, para isso é adequado respeitar algumas premissas básicas, tais como, ter um projeto pedagógico claro e objetivo, reconhecer constantemente os esforços dos docentes e, na medida do possível, fomentar um ambiente de trabalho mais justo e agradável.

Uma equipe formada com docentes preparados é fundamental para o reconhecimento de uma instituição de ensino. Para alcançar esse quadro de docentes altamente qualificados, o trabalho da gestão educacional também deve ser eficiente, para assim selecionar os melhores docentes.

Aos gestores educacionais, os cuidados para manter sua equipe motivada e para reter seus talentos se tornaria mais fácil se, quem recruta esses profissionais, já esteja atento ao perfil do docente desejado, desde o momento do processo seletivo até sua efetiva contratação. De acordo com Mazon; Trevisan (2000), quando o processo de recrutamento e seleção é feito de modo eficaz, o resultado é sentido em toda a instituição. 
Conforme observamos no presente estudo, os discentes entendem como uma boa qualificação docente algumas qualidades pessoais e técnicas para formação profissional, onde os docentes saibam mesclar teoria, prática e sociabilidade, ou seja, saber se relacionar com os discentes para gerar um processo reflexivo durante os contextos de ensino-aprendizagem. Acredita-se estarem evidentes, no contexto pesquisado, os aspectos indispensáveis às qualidades pessoais e técnicas do papel desempenhado pelo (a) 'bom (a) professor (a)' em sala de aula, dentro do processo de ensino aprendizagem, tanto na perspectiva dos formadores de professores como na dos estudantes.

Estes resultados não poderão ser tomados como um padrão generalizado a todos os cursos tecnológicos de gestão, uma vez que as ações dos sujeitos envolvidos em qualquer relação pedagógica determinam e, são determinadas pelo contexto onde estes estão inseridos, como pode ser visto nas palavras de Schwartz; Bittencourt, (2012, p. 09): "as qualidades esperadas de um 'bom professor' variam de acordo com o contexto histórico, cultural e social", mas afirmamos que os resultados ora apresentados geram referências interessantes a contribuir na reflexão sobre o perfil de professores desejados pelos alunos.

Futuros estudos devem se orientar por problemas desta natureza considerando a realidade de outros cursos, bem como, buscando investigar como tais impressões levantadas se modificam ao longo do processo de formação, podendo, até mesmo atingir o nível de egressos.

\section{Referências}

ABREU M. C, MASETTO M. T. Ensino e aprendizagem: o professor universitário em aula: prática e princípios teóricos. São Paulo: MG Editora Assoc.: 1997. p. 3-12.

ANASTASIOU, L. G. C.; ALVES, L. P. (org.). Processos de ensinagem na universidade: pressupostos para as estratégias de trabalho em aula. 5. ed. Joinville: UNIVILLE, 2005.

ANASTASIOU, L.G.C. Ensinar, aprender, apreender e processos de ensinagem. In: ANASTASIOU, L.G.C.; ALVES, L. P. (org.). Processos de ensinagem na universidade: pressupostos e estratégias de trabalho em sala de aula. Joinvile: UNIVILLE, 2010.

ASCHIDAMINI, F.; CRISTIANO, G. D; PERONDI, M. Um demarcador geracional para os jovens universitários. In: RIBEIRO, J. J. et al. (orgs). Juventudes na Universidade: olhares e perspectivas. Porto Alegre: Redes, 2014.

ASSIS, R. M.; BONIFÁCIO, N. A. A produção científica na formação dos alunos do curso de Educação Física do CAJ/UFG. Itinerarius Reflectionis, Jataí, v. 2, n. 5, jul./dez. 2008.

Disponível em: https://www.revistas.ufg.br/rir/article/view/20419/19177. Acesso em: 14 out. 2021.

BARBOSA, M. S. S. O papel da escola: obstáculos e desafios para uma educação transformadora. 2004. Dissertação (Mestrado em Educação) - Universidade Federal do Rio Grande do Sul, Porto Alegre, 2004. Disponível em: https://lume.ufrgs.br/handle/10183/6668. Acesso em: 14 out. 2021.

BOCK, A. M. B.; FURTADO, O.; TEIXEIRA, M.L.T. Psicologias: uma introdução ao estudo da psicologia. São Paulo: Saraiva, 2011. 
BORDENAVE, J. D.; PEREIRA, A. M. Estratégias de ensino-aprendizagem. 24. ed. Petrópolis: Vozes, 2002.

BRASIL. Lei n. 9.394, de 20 de dezembro de 1996. Lei de Diretrizes e Bases da Educação. Diário Oficial da União. Brasília, DF, 1996. Disponível em:

http://www.planalto.gov.br/ccivil_03/leis/19394.htm. Acesso em: 27 out. 2021.

BRIDI, J. C. A. A iniciação científica na formação do universitário. 2004. Dissertação (Mestrado Educação) - Universidade Estadual de Campinas, Faculdade de Educação, Campinas, 2004. Disponível em:

http://repositorio.unicamp.br/jspui/handle/REPOSIP/253212. Acesso em: 27 out. 2021.

CHRISTOPHE, M. A legislação sobre a educação tecnológica, no quadro da educação profissional brasileira. Rio de Janeiro: IETS, 2005. Disponível em:

http://www.iets.org.br/biblioteca/A_legislacao_sobre_a_educacao_tecnologica.pdf. Acesso em: 14 out. 2021.

CHRISTI, M. Empatia. 2015. Disponível em: http://kdfrases.com/usuario/ATSB/frase/1137f. Acesso em: 27 out. 2021.

COUTINHO, M. P. L.; BÚ, do E. A Técnica de Associação Livre das Palavras sobre o Prisma do Software Tri-Deux-Mots (Versão 5.2). Revista Campos do Saber, São Paulo, 2017.

Disponível em: http://periodicos.iesp.edu.br/index.php/campodosaber/article/view/72. Acesso em: 14 out. 2021.

COVEY, S. Os 7 hábitos das pessoas altamente eficazes. 52. ed. Rio de Janeiro: BestSeller, 2014.

DELORS, J. Educação: um tesouro a descobrir. 7. ed. São Paulo: Cortez, 2012.

DEMO, P. Educar pela pesquisa. Campinas: Autores Associados, 2005.

FÁVERO, M. L. A. Produção e apropriação do conhecimento da universidade. In:

MOREIRA, A. F. B. (org.). Conhecimento educacional e formação do professor: questões atuais. São Paulo, SP: Papirus, 1994. p. 53-70.

FREIRE, P. Professora sim, tia não: cartas a quem ousa ensinar. 10. ed. São Paulo: Olho d'água, 1993.

FREIRE, P. Pedagogia da autonomia. Rio de Janeiro: Paz e Terra, 1998.

FUKUDA, C. C.; PASQUALI, L. Professor eficaz: um instrumento de aferição. Avaliação Psicológica, v.1, n.1, 01-16, 2002. Disponível em:

http://pepsic.bvsalud.org/scielo.php?script=sci_arttext\&pid=S167704712002000100002\&lng $=$ pt\&nrm=is. Acesso em: 14 out. 2021.

GARGALLO, B. et al. El cuestionario CEMEDEPU. Un instrumento para la evaluación de la metodología docente de los profesores universitarios. Revista Española de Pedagogía, 2009. 
Disponível em: https://revistas.unav.edu/index.php/estudios-sobreeducacion/article/view/4397. Acesso em: 27 out. 2021.

GIL, A. C. Didática do Ensino Superior. 1. ed. São Paulo: Atlas, 2008.

IMBERNÓN, F. Formação docente e profissional: formar-se para a mudança e a incerteza. 6. ed. São Paulo: Cortez, 2006.

ISAIA, S. M. A. Verbetes. In: CUNHA, M. I.; ISAIA, S.; MOROSINI, M. (org) Enciclopédia de Pedagogia Universitária: Glossário. Brasília/INEP, 2006.

KUENZER, A. Z. A reforma do ensino técnico no Brasil e suas consequências. Ensaio: Políticas Públicas em Educação, Rio de Janeiro, v. 6, n. 20, p. 365-384. jul./set. 1995. Disponível em: http://www.ia.ufrrj.br/ppgea/conteudo/T2-

1SF/Sandra/A\%20reforma\%20do\%20ensino\%20t\%E9cnico\%20no\%20Brasil.pdf. Acesso em: 27 out. 2021.

LAZZARIN, H. C.; NAKAMA, L.; CORNONI JUNIOR, L. O papel do professor na percepção dos estudantes de odontologia. Saúde e Sociedade, v. 16, n. 1, p.90-101, 2007. Disponível em: https://doi.org/10.1590/S0104-12902007000100009. Acesso em: 27 out. 2021.

LOPES, A. H. R. G. P. A pedagogia no divã: a Educação e a psicanálise de mãos dadas na busca pela emancipação dos educandos. Cadernos da pedagogia, São Carlos, v. 5, n. 10, jan/jun., p. 2-17, 2012. Disponível em:

http://www.cadernosdapedagogia.ufscar.br/index.php/cp/article/view/229. Acesso em: 27 out. 2021.

LOPES, E. C. P. M.; CAPRIO, M. As influências do modelo neoliberal na educação. Revista online de Política e Gestão Educacional, Araraquara, n. 5, p. 1-16, 2008. Disponível em: https://periodicos.fclar.unesp.br/rpge/article/view/9152. Acesso em: 14 out. 2021.

MARTINS, M. M. Uma crise nas instituições. Lisboa: Universidade de Lisboa, 2004.

MAICAS, G.S. Eficacia de la enseñanza. In: Psicología de la educación. Tomo II. Madrid: Universidad Nacional de Educación a Distancia, 1996.

MAZON, L.; TREVIZAN, M. A. Recrutamento e seleção de recursos humanos em um hospital psiquiátrico de um município paulista. Rev. Latino-am. Enfermagem, Ribeirão Preto, v. 8, n. 4, p. 81-87, agosto 2000. Disponível em:

https://www.researchgate.net/publication/237364613_Recrutamento_e_selecao_de_recursos_ humanos_em_um_hospital_psiquiatrico_de_um_municipio_paulista. Acesso em: 27 out. 2021.

MEIRIEU, P. O cotidiano da escola e da sala de aula: o fazer e o compreender. Porto Alegre: Artmed, 2005.

MORIN, E. A cabeça bem-feita: repensar a reforma - reformar o pensamento. Rio de Janeiro: Bertrand Brasil, 2000. 
NEVES, C. E. B. Universidade brasileira: equidade, qualidade e cidadania. Coimbra: CES, 2004. Disponível em:

http://www.ces.uc.pt/lab2004/inscricao/pdfs/painel44/ClarissaNeves.pdf. Acesso em: 14 out. 2021.

NÓVOA, A. Os professores e a sua formação. Lisboa: Dom Quixote, 1992.

NÓVOA, A. Formação de professores e profissão docente. In: NÓVOA, A. Os professores e a sua formação. Lisboa: Dom Quixote, 1995.

OLIVEIRA, M. K. O problema da afetividade em Vygotsky. In: LA TAILLE, Y. (org.). Piaget, Vygotsky e Wallon: Teorias Psicogenéticas em discussão. São Paulo: Summus Editorial, 1992.

PENIN, S. T. de S. A formação de professores e a responsabilidade das universidades. Educação Superior, v. 15, n. 42, ago. 2001. Disponível em: https://doi.org/10.1590/S010340142001000200017. Acesso em: 14 out. 2021.

PERRENOUD, P. Construir as competências desde a escola. Porto Alegre: Artmed, 1999.

PERRENOUD, P. A construção do conhecimento em sala de aula. Porto Alegre: Artmed, 2000 .

SANTOS, A. R. Metodologia científica: a construção do conhecimento. Rio de Janeiro: DP \& A, 2004.

SANTOS S. C. O Processo de Ensino: Aprendizagem e a Relação Professor- Aluno: aplicação dos "Sete Princípios Para a Boa Prática na Educação de Ensino Superior". Caderno de Pesquisas em Administração, São Paulo, v. 08, n. 1, jan./mar. 2001.

SCHWARTZ, S.; ALONSO, T. J. Entre a indignação e a esperança: motivação, pautas de ações docentes e orientação paradigmática na alfabetização de jovens e adultos. 2007. Tese (Doutorado) - PUCRS, Porto Alegre, 2007.

SCHWARTZ, S.; BITTENCOURT, A. Z. Quem é o "bom professor" Universitário? In: SEMINÁRIO DE PESQUISA EM EDUCAÇÃO DA REGIÃO SUL, 2012, Caxias do Sul. Anais [...]. Caxias do Sul: UCS, 2012. Disponível em http://www.ucs.br/etc/conferencias/index.php/anpedsul/9anpedsul/paper/viewFile/1423/976. Acesso em: 14 out. 2021.

SILVA, E. C. da S.; ZUCOLOTTO, M. P. R. Percepções dos Docentes sobre Afetividade no Ensino Superior em um Curso da Área da Saúde. Revista de Psicologia, v. 13, n. 44, 2019. Disponível em https://idonline.emnuvens.com.br/id/article/view/1599/2457. Acesso em: 14 out. 2021.

SUDBRACK, E. M.; NEGRO, A. Internacionalização e Educação: impactos nas políticas educacionais. RP3 - Revista de Pesquisa em Políticas Públicas, n. 07, 2016. Disponível em: http://periodicos.unb.br/index.php/rp3/article/view/18620/3719. Acesso em: 14 out. 2021. 
VYGOTSKY, L. S. A formação social da mente. São Paulo: Martins Fontes, 1998.

WALLON, H. A evolução psicológica da criança. Lisboa: Edições 70, 1968.

Recebido em maio de 2021.

Aprovado em outubro de 2021. 